\title{
TEACHING GEOMATICS FOR GEOHAZARD MITIGATION AND MANAGEMENT IN THE COVID-19 TIME
}

\author{
M. Scaioni ${ }^{1}$, L. Longoni ${ }^{2}$, L. Zanzi ${ }^{2}$, V. Ivanov ${ }^{2, *}$, M. Papini ${ }^{2}$ \\ ${ }^{1}$ Politecnico di Milano, Department of Architecture, Built Environment and Construction Engineering \\ via Ponzio 31, 20133 Milano, Italy - marco.scaioni@polimi.it \\ 2 Politecnico di Milano, Department of Civil and Environmental Engineering \\ piazza L. da Vinci 32, 20133 Milano, Italy - \{laura.longoni, luigi.zanzi, monica.papini, vladislaviov.ivanov\}@polimi.it
}

\section{Commission IV}

KEY WORDS: Active-Learning, Geomatics, Geophysics, Landslides, Monitoring, Problem-Based Learning, Risk Mitigation, Teaching

\begin{abstract}
:
Starting from the Academic Year 2018-2019, Politecnico di Milano university has established a BSc programme on "Civil Engineering for Risk Mitigation” (ICMR). This course is aimed at training students to cope with issues related to different types of natural and anthropogenic hazards, among which Geohazards are paid a primary attention. A "Workshop on Monitoring Techniques for Geohazards" is included to present different Geological, Geophysical and Geodetic techniques to be applied to landslides within an integrated approach. The use of active and problem-based learning techniques was one of the basic principles in the design of ICMR programme. This resulted in planning some visits and field campaigns to allow students to directly work on real case studies. The course has been scheduled for the first time in the second term of A.Y. 2019-2020, when the COVID-19 pandemics developed and prevented the lab activities in the field to be implemented as planned. The paper presents how the content and the organization of the course have been revised to try to reach the same learning objectives notwithstanding the limitations on the activities "in presence."
\end{abstract}

\section{INTRODUCTION}

Starting from the Academic Year 2018-2019, Politecnico di Milano university has established a BSc programme on "Civil Engineering for Risk Mitigation” ("Ingegneria Civile per la Mitigazione del Rischio - ICMR”). This programme, organized on Lecco Campus, is aimed at training students to be prepared coping with issues related to different types of natural and anthropogenic hazards, among which Geohazards are paid a primary attention. ICMR is extending the university offer in this domain since a MSc on the same subject (CERM) has been already activated since the A.Y. 2008-2009 (Politecnico di Milano, 2020a). At MSc level all courses are taught in English, while at BSc level they are taught in Italian.

The experience achieved in the previous years in teaching to MSc students at CERM has been transferred to the new BSc programme. In particular, attention has been paid to lab activities, which are really effective for communicating methods for Geohazards investigation (see, e.g., Scaioni et al., 2017; 2018). In addition, the concept of the entire new BSc programme ICMR was given a marked innovative character, following the trend fostered by Politecnico di Milano towards modernization of teaching methods (Duò, 2019). The application of active and problem-based learning (PBL, see Alvarez-Taboada, 2019) was encourage and tentatively implemented in the design of the new programme.

The structure of ICMR programme is based on two parallel tracks: one focusing on "Geohazards" ("Dissesto Idrogeologico") and the other on "Structures and Infrastructures" (“Strutture e Infrastrutture”), see Politecnico di Milano (2020b).
Geomatics is included in both the developed curricula since the use of Geographic Information (GI) at different scales is today of fundamental relevance when dealing with hazards. In particular, beyond the basic courses on "GIS and Geostatistics" scheduled on the first year, some practical workshops and laboratories are activated on the second and third years.

In this paper we would like to report about one of these courses entitled "Workshop on Monitoring Techniques for Geohazards" ("Tecniche di monitoraggio del dissesto idrogeologico"). This workshop belongs to the track on "Geohazards," but it has a dual version in the parallel track "Structures and Infrastructures." It is composed of three submodules: "Geodetic monitoring," "Geophysics," and "Application of monitoring techniques to landslides." In Section 2, these individual modules are briefly described. In all of them, the concept is to present different types of investigation methods and to apply them to landslides within an integrated approach. Applications should consider some real cases, also to be afforded with specific visits and data acquisition campaigns. The Lecco Campus is located at the border with the Prealps Mountain region and close to the Alps, making easy the organization of field activities.

The "Workshop on Monitoring Techniques for Geohazards" has been scheduled for the first time in the period from March-June 2020. The COVID-19 pandemics that cropped up worldwide during the same period prevented the developing of the activities as planned. All courses at Politecnico di Milano have been quickly transformed from "in presence" into remote learning, without any chance to carry out technical visits and to organize field labs as scheduled. This new and unexpected challenge required to deal with two categories of problems. The

\footnotetext{
* Corresponding author
} 
first one concerned the revision and reformulation of the course design and content. Two main questions posed by the lecturers of the integrated course were:

1. How to let students do practical experience without the chance to go in the field?

2. How to keep the integration between different investigation techniques and Geohazards (in particular with landslides)?

The answer to both questions was tentatively found by defining a real case study to be afforded in virtual way, in order to be COVID-19 compatible. This consisted in an active landslide located in the northern sector of the Italian Prealps (the "Pruna" landslide), see Subsection 3.2. Using the available literature and the existing data, students could reach a deep insight into the physical processes and could apply some geotechnical modelling methods. On the other hand, they had to propose some solutions for the assessment and monitoring of this landslide by using inputs learnt in "Geophysics" and "Geodetic Monitoring” submodules, respectively. In the final part of the course, students were split into working groups made up of 2-4 people. An assignment was given to each of them. The aim of these assignments was to train the capability of focusing into some specific investigation techniques and problems, going beyond with respect to the theoretical and methodological inputs learnt during online lectures. The concept was to invite students to do things and to think about what they are doing. The topics of the assignments are described in Section 3.

The second category of problems concerned the used of appropriate tools for remote learning. In Barrionuevo (2019) an overview about this topic is given, while Yordanov et al. (2019) report about a related experience.

The paper would present the content and the organization of the "Workshop on Monitoring Techniques for Geohazards" and its assignments, but also to discuss the results obtained in terms of learning objectives.

\section{CONTENT OF THE COURSE SUBMODULES}

\subsection{Geodetic monitoring}

The submodule on "Geodetic Monitoring" (lecturer Prof. M. Scaioni) has the aim of providing a background on traditional and advanced surveying techniques, and to introduced how they can be used for deformation monitoring. Students have already followed a course on "GIS and Geostatistics" on the first year, so that they are expected to share a background on basic statistics, variance-covariance propagation, Least-Squares adjustments, and statistical inference.

The three main surveying techniques that are analysed in the submodule are based on measurements with total stations, optical levelling and GNSS (Global Navigation Satellite Systems). Techniques for collecting point clouds, such as photogrammetry and laser scanning, are not presented here. Indeed, these topics will be included in a lab on the third year for those students following the track on "Geohazards."

Theoretical and methodological topics are introduced in frontal lectures, which have been organized online. The "switch-todigital" has required a complete revision of the teaching material with respect to that already prepared for lectures "in presence.” In particular, the segmentation of each topic in smaller subtopics and the use of other material from social media has revealed to be very useful to make simpler the understanding process by students.

Before the change imposed by the COVID-19 pandemic, the submodule on "Geodetic Monitoring" should have presented some practical activities in the field. First of all, these activities should have the aim of training students in using surveying instruments and to process collected data. In addition, some of them were planned to be organized in specific geological sites, to let students become familiar with problems related to Geohazards. This initial organization was turned into digital. The used of instruments was shown by using pre-recorded videos and live lectures where their use was demonstrated by lecturers form the university lab. In fact, during the whole pandemic, the access to the university premises always remained open. The in-field experience was supplied by the assignments that will be described and discussed in Section 3.

\subsection{Geophysics}

The objective of the submodule on "Geophysics" (Lecturer Prof. L. Zanzi) is to make the future professionals able to apply the proper geophysical investigation and monitoring methods to hydrogeological problems. Students of this submodule are supposed to become future professionals that might be direct users or end-users of geophysical technologies. Thus, the submodule provides a background on the geophysical methods more frequently applied to study hydrogeological problems, i.e., seismic methods, electrical methods, Ground Penetrating Radar (GPR), and tomographic methods. For each method, physical principles and equipment are illustrated and the students are trained to properly design the acquisitions and to interpret the recorded data.

As for the "Geodetic Monitoring" submodule, this one was also re-designed to face the COVID-19 emergency. Videos and application examples were widely used to supply the planned field activities. Recent activities of the Geohazard Group at Politecnico di Milano were presented as case studies to show a few real examples of ongoing monitoring systems (Arosio et al., 2017; 2018; Hojat et al., 2019; Zhang et al., 2019). The final assignments were designed on the real case study discussed in Section 3 so that the students had the opportunity to see how geodetic and geophysical methods may be integrated to characterize and monitor a real hydrogeological problem.

\subsection{Application of monitoring techniques to landslides}

This submodule aimed at introducing the vast realm of landslide phenomena to the students. A background on the differentiation between the different types of landslides (Hungr et al., 2014) was followed by the description of their respective triggering mechanisms and consequently, the monitoring techniques required for each phenomenon. Those may include the observation of displacement, vibration, ground water table level, precipitation, etc. Since these quantities can be derived from techniques used in the previously described submodules, the course on "Application of monitoring techniques to landslides" provides a playground for the integration of various competences towards the problem of landslide monitoring. Ideally, apart from the frontal lectures and exercises, the course would have included field activities where students are able to observe a real landslide and get a hands-on experience with geological, geophysical, and geodetic techniques. The switch to an online-only course required the redesign of those activities. In order to keep the course application-oriented, raw landslides 
monitoring data from different monitoring tools were provided to the students with the aim to train them on processing methods and to carry out a critical analysis of each landslide phenomenon. Learning activities involved the use of video material with examples of landslides. Video examples of experimental activities at the laboratory scale were also considered a suitable way to convey the concepts explained during the course (e.g., Ivanov et al., 2020).

\subsection{Student evaluation and quality assessment}

The interchange between different submodules presented in the previous subsections mainly happened in the final stage on the basis of some assignments. Despite of this, transmitting the idea that thematic submodules were part of a unique course was a primary goal of the lecturers. In our opinion the achievement of this goal was incomplete, waiting for the results of the quality assessment that usually is done in the end of the course through a form with fixed questions, and a space for free comments. The outcomes of the quality assessment related to the first edition of the course is not yet available at the moment of writing.

The final evaluation of students was separately conducted in each submodule. The final result consisted in the average score obtained in the three submodules. This is also an aspect to be modified in the future by introducing a public presentation with contents transversal to all submodules, followed by individual exams.

\section{ASSIGNMENTS}

\subsection{Overview and concept}

The assignment of some projects to be developed in the period after lectures is a typical and effective solution in university courses, summer schools and other training initiatives (see, e.g., Rutzinger et al., 2016).

All students were provided with a presentation of geological conditions, problems and outputs from real monitoring observations related to the study case presented in Subsection 3.2. Geographic data from the regional Geoportal (Regione Lombardia, 2020) could be also retrieved. Indeed, during the first year of the ICMR programme, students have already followed a course on "GIS and Geostatistics", where they have trained in using GI and GIS, as well as those fundamental statistical techniques to be used in Geomatics (Politecnico di Milano, 2020b).

Final assignments were organized here in order to make students work on a common case study, to be afforded from different sides. Each assignment was appointed to a working group made up of 3-4 students and consisted in three parts, which did correspond to the submodules of the course listed in Section 2. After the presentation of the case study, in this subsection the focus is given to the geodetic monitoring component of each assignment. In the end, assignments on "Geophysics" are briefly reported.

Some questions were posed to drive the design of each geodetic monitoring system. Three out of them were common to all assignments:

1. Definition of goals and performances of the adopted geodetic monitoring system;

2. Selection of the equipment; and
3. Measurement rate as function of the expected displacements.

The assigned monitoring system could not be changed in favour of another solution that was retained as more appropriate for the case study. On the other hand, students should draw some conclusions on the effective applicability of the assigned technical solution and could possibly propose the application of another more efficient method.

Each assignment deals with a specific content of applied Geodesy to be analysed and developed. It should be remarked that students were provided with the necessary background to cope with the assigned problem. On the other hand, in a PBL fashion, they were supposed to go deeper in the topic to afford and to learn by themselves all necessary technical details. Of course, this task was supported and guided by tutors.

\subsection{The study case}

The study case is located in the Tartano valley (see Fig. 1). This small Prealpine valley aside of the much larger Valtellina valley has been the object of a number of studies due to the presence of a variety of hydrogeological phenomena, ranging from intense sediment transport, soil slips, debris flows, as well as a deep seated gravitational slope deformation (DSGSD), see Ballio et al. (2010), Longoni et al. (2016), Yordanov and Brovelli (2020a), and Yordanov and Brovelli (2020b)). The "Pruna Landslide" is a complex rockslide with dimensions of approximately $600 \mathrm{~m} \times 700 \mathrm{~m}$, see Figure 2. The currently active lower part has dimensions of $270 \mathrm{~m}$ x $200 \mathrm{~m}$. The depth of the landslide is still not clearly defined but evidence from geophysical observations estimated it to be around $100 \mathrm{~m}$. This landslide is not the only one in the Valtellina region as the origin of such phenomena is related to the presence of faults in the area, which define weak zone scarp characterized by rock with poor geo-mechanical properties and low permeability. Historically, the landslide has been reactivated in 1993 and 2000 after the occurrence of heavy precipitation events. This was evidenced by a several hundred meters long opening at the scarp. Since 2002 the landslide displacements have been progressively decreasing with an yearly average displacement of about $1 \mathrm{~cm}$.

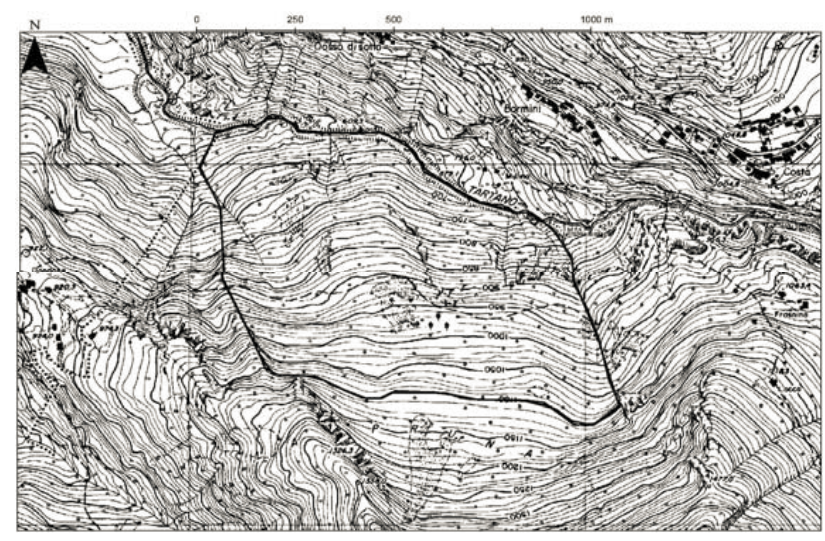

Figure 1. Map at scale 1:10,000 of the area of "Pruna

Landslide” (Tartano Valley, Italy) proposed as case study for the assignments (lat: $46.130512^{\circ} \mathrm{N}$; lon: $9.6501159^{\circ} \mathrm{E}$ ). 


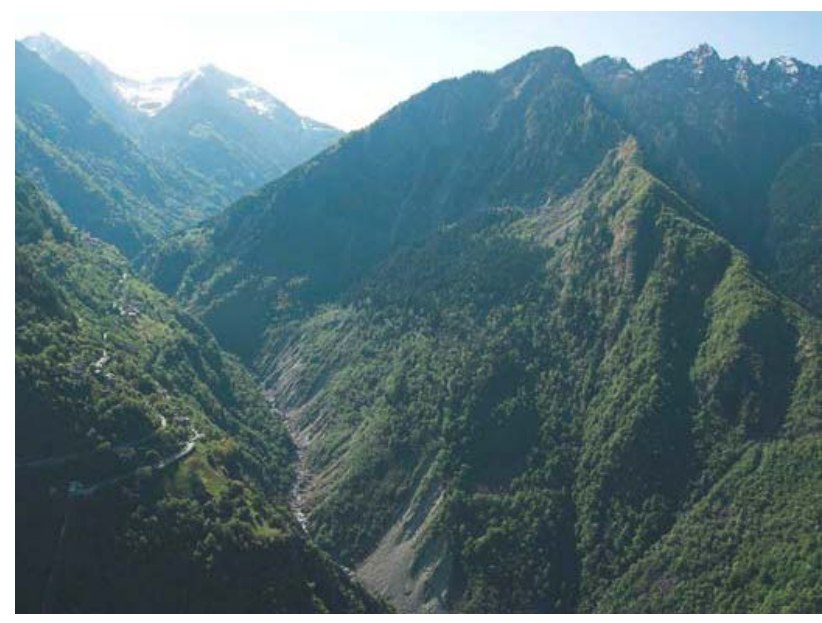

Figure 2. The "Pruna Landslide.”

\subsection{Presentation of the assignments (Geodetic Monitoring)}

3.3.1 Assignment 1 - Deformation monitoring based on a robotic total station: The goal of this assignment was to design a monitoring system based on a robotic total station (RTS) to be permanently installed in front of the landslide (see Frukacz et al., 2016; Lienhart, 2017). This system would be supposed of measuring 3D displacements of control points (CPs) positioned on the landslide surface. A short observation period (in the order a few months) was proposed. On the basis of the geological analyses, students should plan the data acquisition rate and the layout of reflectors to be used as CPs. In addition, some reference points located outside the slope should be placed for calibration purpose. The design of this monitoring system was guided by the following specific questions, in addition to the general ones already presented at the beginning of this subsection:

1. CP positioning and selection of the RTS location; and

2. Estimate of the theoretical accuracy of $3 \mathrm{D} C P$ coordinates based on variance-covariance propagation (Schofield, Breach, 2007).

3.3.2 Assignment 2 - Measurement of vertical displacements by means of optical levelling: The goal of this assignment was to measure vertical displacements of the slope on the basis of the periodical repetition of optical levelling campaigns (Schofield, Breach, 2007; Limpach et al., 2016). This monitoring solution is thought to be applied in the long term (years) with repeated observations to be accomplished on a regular basis, but with a rate not higher than one campaign per month. The following specific questions were posed:

1. Design of optical levelling lines on a Digital Terrain Model (DTM);

2. $\mathrm{CP}$ and reference benchmark positioning; and

3. Simulation of the theoretical accuracy of CP heights as obtainable from Least-Squares adjustment (Wolf, Ghilani, 1997).

In this case, students should decide how many and where levelling lines could be positioned, keeping into consideration the geometry and the safe accessibility to the landslide body, but trying also to collect relevant observations about ongoing vertical soil deformation.
3.3.3 Assignment 3 - Measurement of 3D displacements by means of repeated GNSS control network: The goal of this assignment was to design a monitoring system based on the periodical repetition of a high-precision GNSS control network (see Hofmann-Wellenhof et al., 2008). This monitoring solution is thought to be applied in the long term (years) with repeated observations of the network to be accomplished on a regular basis, but with a rate not higher than one campaign every two months. The following specific questions were posed:

1. Positioning of CPs on the landslide body and selection of the reference points in stable areas in the nearby of the landslide;

2. GNSS control network design;

3. Georeferencing of the GNSS network with respect to the Italian geodetic reference frame (RDNETRF2000.8, see Baroni et al., 2008); and

4. Simulation of the theoretical accuracy of 3D CP coordinates as achievable from Least-Squares adjustment.

3.3.4 Assignment 4 - Deformation monitoring based on GNSS-RTK permanent system: The goal of this assignment was to design a monitoring system based on the continuous acquisition of differential GNSS observations (see Cefalo et al., 2018). In such a case, attention should be paid on the structure of the permanent monitoring system. The following specific questions were posed:

1. Positioning of rover GNSS receivers to be used as CPs on the landslide body and selection of the location for the master GNSS station;

2. Selection of the data transmission methods for master-rover communication and to connect to the control unit from remote; selection of the energy supply solution;

3. Selection of differential GNSS mode to be applied (Real-Time Kinematic - RTK - or quasi-static data processing of contemporary observations recorded from each rover and the master GNSS station, see Limpach et al., 2016) depending on the velocity of landslide deformations; and

4. Sky-visibility analysis of GNSS constellations.

In this assignment, the attention of student was tried to be focused on the definition of a few aspects that were retained crucial for the implementation of an effective GNSS monitoring system. In particular, the analysis of sky-visibility was retained very important for the decision about master's and rovers' locations. In order to carry out this kind of analysis, the free online service provided by Navmatix (2020) was suggested. This tool allows to analyze the GNSS satellite visibility and its expected quality in term of Dilution-of-Precision (DoP - see Hofmann-Wellenhof et al., 2008) by considering also the presence of physical obstacles around the GNSS receiver.

\subsection{Results}

The delivery of each assignment consisted in a technical report and a presentation supported by slides. On the basis of these two elements, the final projects were evaluated and the final score of the course assigned to each student. This also comprehended the evaluations of some intermediate lab activities carried out during the term.

3.4.1 Assignment 1: The group committed with this topic based the design of the monitoring system on a RTS Viva TS16 by 
Leica Geosystems (2020a). A total number of 44 reflectors were placed as CPs and reference points for environmental calibration purpose (see Fig. 3). The RTS is placed on a concrete pillar in a protected hut, in a location that is not far away from a village. The average distance of the RTS from CPs is $1.4 \mathrm{~km}$. The acquisition rate was defined under two possible scenarios: (1) if the current landslide velocity (approx. 1 $\mathrm{cm} /$ year) persists, one measurement per day is recorded; (2) in periods of intense precipitations or in the case of accelerated slope displacements, the measurement rate is increased up to one epoch every three hours (8 observation epochs per day).

In the last part of the assignment, students have applied variance-covariance propagation to compute the theoretical accuracy of observed 3D CPs on the basis of the instrumental performances and the measurement layout. This resulted in the definition of the error ellipses at predefined confidence level.

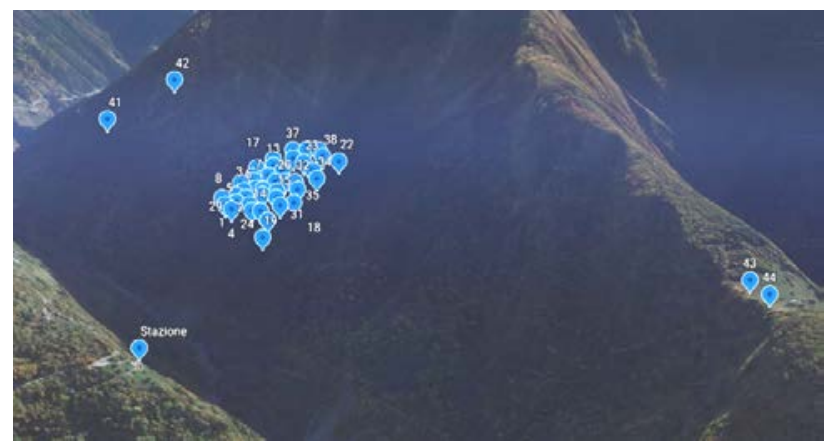

Figure 3. Locations of the robotic total station (RTS), control points (CPs) on the landslide body and reference points for environmental calibration on stable areas (No. 41-44).

3.4.2 Assignment 2: The design of the optical levelling measurement scheme was based on the use of a DTM of the slope, from which contour lines interspaced by a vertical $2 \mathrm{~m}$ interval were extracted in QGIS open-source environment (QGIS Development Team, 2020). One applicable solution was found by drawing two independent optical levelling lines at different average heights: "Line 1" was made up of 27 CPs at approx. $987 \mathrm{~m}$ a.s.l., and "Line 2" at approx. 1,125 m a.s.l. (\#26 CPs). Each levelling line ends on a benchmark located in a stable area outside the landslide niche, as it can be seen in Figure 4 for Line 1 . The selected equipment to carry out data acquisition included an automatic optical level NAK2 by Leica Geosystems (2020b) able to estimate readings at $0.01 \mathrm{~mm}$ precision. A pair of $2 \mathrm{~m}$-long rods with invar graduation were proposed to be used.

Data processing consisted first in the definition of some tolerances to check out the presence of gross errors during field campaign. The second step was the estimate the achievable relative accuracy of the $\mathrm{CP}$ heights with respect to the reference benchmarks.

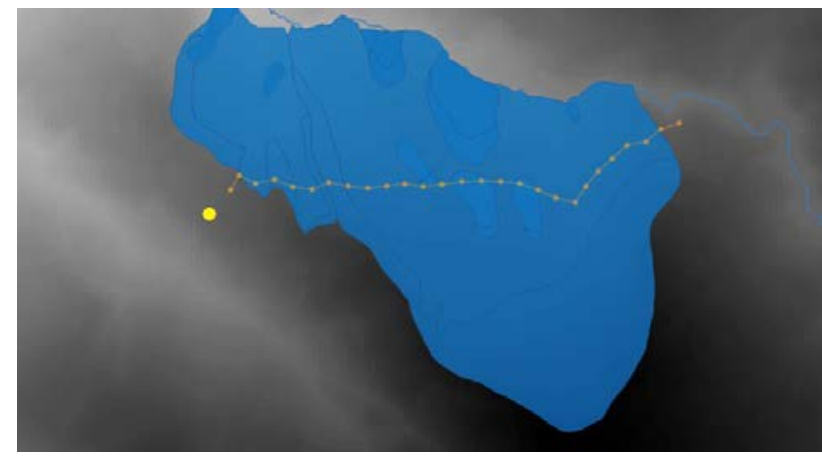

Figure 4. Optical levelling Line 1 crossing the landslide body at an average height of $987 \mathrm{~m}$ a.s.l. Small dots represent

intermediate CPs (\#27), while the bigger yellow dot on the left side is the reference benchmark.

3.4.3 Assignment 3: The design of a static GNSS network for 3D deformation measurement led to plan 4 CPs in accessible regions of the landslide body. Two additional points were located outside the landslide area in stable regions. The resulting 6-points GNSS network is measured by recording 15 independent baselines. The schedule of data acquisition sessions considering the use of three geodetic receivers was also studied. The georeferencing of this network in the ETRF 2000.8 geodetic frame is obtained by measuring three baselines between some points of the network and some permanent CORSs (Continuously Operating Reference Stations) of the public positioning service SPIN3 GNSS (2020).

The computational part of the assignment consisted in estimating the theoretical accuracy of CP coordinates as achievable from Least-Squares adjustment. This problem was solved by implementing the matrix computation in Microsoft Excel ${ }^{\circledR}$ worksheet. The crucial point was given by the definition of a priori covariance matrices for the GNSS baselines. Two hypotheses were made about the covariance matrices: (1) uncorrelated components (not realistic); and (2) correlated components. The obtainable covariance matrix $\mathbf{C}_{\mathbf{x x}}$ of the unknown 3D point coordinates could be estimated on the basis of the network geometry defined by the design matrix and in the case of no gross errors (unary sigma nought). The covariance matrix $\mathbf{C}_{\mathbf{x x}}$ was computed under both assumptions (1) and (2) in order to compare the results.

3.4.4 Assignment 4: The group in charge with this topic designed an RTK-GNSS continuous monitoring system to measure 3D point displacements in correspondence of 6 rover stations on the landslide body. Leica Geosystems GMX910 smart-antennas (with incorporated GNSS receiver) were selected to serve as rover stations. These CPs are placed in representative locations of the different sectors of the slope under investigation, as depicted in Fig. 5. A master station equipped with a GNSS receiver model GM30 of the same brand was planned on the opposite flank of the valley, coupled with an antenna model AR20. Technical details about the selected equipment can be found at Leica Geosystems (2020c). After an analysis of different solutions for the connection between master and rover receivers, a radio link was proposed. 


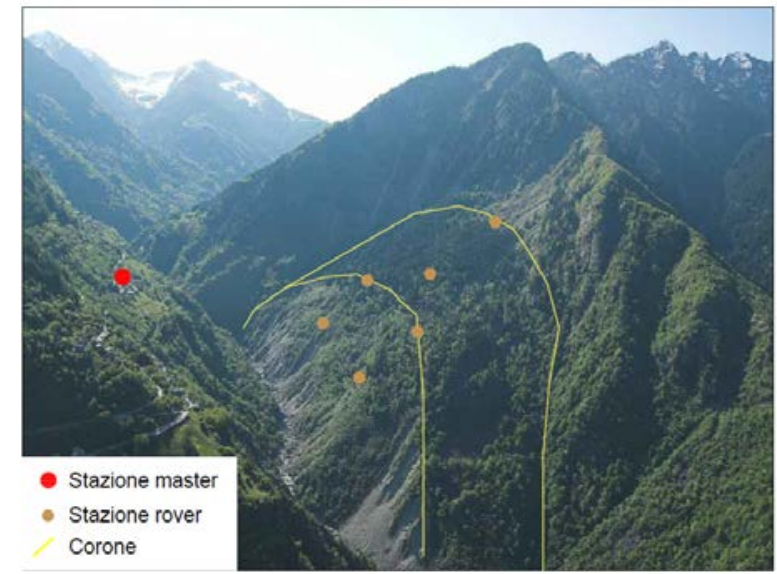

Figure 5. Locations of the GNSS rover antennas in correspondence of CPs (brown dots) on the landslide body and the reference master station (red point) on the opposite flank of the Tartano Valley. The upper limit of two existing niches of the landslide body are overlaid (yellow lines).

An important part of this assignment was related to the analysis of satellite visibility from selected GNSS stations within time. This was accomplished by using the online free service provided by Navmatix (2020). Input data were the approximate 3D locations of adopted GNSS stations, the constellations to be used (GPS, Glonass, Galileo and Beidou) and the location of topographic obstacles in the nearby. Actually, the DTM could not be used as input, but only a few rectangular solids could be drawn. Students managed to insert some simplified obstructions to simulate the effect of terrain topography. The obtained results provided different types of information related to a standard observation day: (a) number of visible satellites; (b) DOP indices; (c) visible satellites; and (d) elevations of visible satellites. These outputs could be compared in both cases when obstacles were used or not in sky-visibility analysis. In Figure 6, the number of visible satellites (a) from the upper rover station on the landslide body is shown. Even though the simplified obstacles cannot exactly reconstruct the real occlusions due to terrain topography, the impressive drop in term of sky-visibility when accounting for the presence of obstacles is dramatically demonstrated.

\subsection{Results from other submodules}

Even though the attention of this paper is mainly on Geomatics, an important characteristic of the "Workshop on Monitoring Techniques for Geohazards" is the interdisciplinary approach. This also reflected on the final assignments, where the same case study (the "Pruna" landslide) was the occasion for students to deal with problems on Geology and Geophysical monitoring techniques.

The selected case study was appropriate to assign to the student groups the design and the simulation of some seismic tests with the objective of confirming and extending the supposed geological model derived from the surface observations and from the borehole data and to characterize the model with geophysical parameters like layer depths, seismic velocities, and Poisson ratio. Assignments included refraction tests with both pressure and shear waves, a reflection test and a check shot in the available borehole. For each test, students were asked to design the acquisition parameters and to generate synthetic data according to the supposed geological model and then to evaluate the accuracy of the results and how this is affected by the expected noise level.

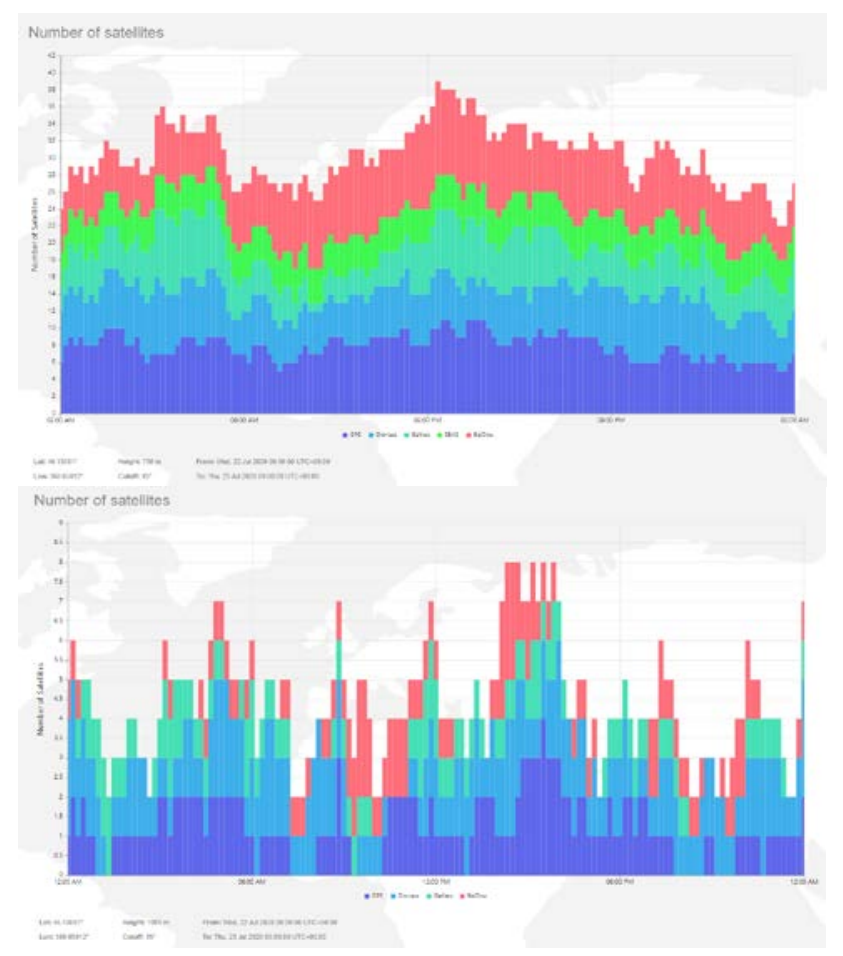

Figure 6. Analysis of the number of visible satellites from the rover station in the upper position on the landslide body, as obtained from Navmatix (2020). A time span of 24 hours was considered. In the results shown in the upper subfigure, no obstacles are considered; in the ones reported in the lower part, some simplified blocks were included to simulate the effect of terrain topography.

\section{LESSONS LEARNT AND CONCLUSIONS}

In this paper we presented the story of the first edition of the "Workshop on Monitoring Techniques for Geohazards" included in the BSc programme on "Civil Engineering for Risk Mitigation - ICMR" at Politecnico di Milano, Italy. Originally planned to be a problem-based learning (PBL) course with a relevant activity in the field, the development of COVID-19 pandemic constrained to move it to a completely online modality. The "switch-to-digital" represented a big challenge, since all laboratory activities could not be directly followed by students.

The consequent re-organization of the course implied the revision of lectures, to be structured in smaller learning modules. Each of them was taught online, without using prerecorded videos. Lectures were supported by slides including video-links from social medias to present specific topics. The opportunity for lecturers to enter the university premises also during the complete lockdown period allowed organizing some practical sessions where the equipment could be presented in interactive way. Data from previous field campaigns were provided to students for training at data processing stage.

In the last weeks of the course, a landslide was proposed as case study to be afforded under Geological, Geophysical and Geodetic Monitoring sides. Students worked in small groups at their homes, communicating and exchanging documents on the 
basis of Microsoft Teams ${ }^{\circledR}$ online platform. Though limited to the design of monitoring systems and other investigations for Geological and Geophysical assessment, the results of these assignments were quite impressive. Each project required to go beyond the theoretical background learnt during lectures. This promoted the cooperation among students and the capability of group working.

At the time of writing it is not possible to envisage how conditions during the next edition of the "Workshop on Monitoring Techniques for Geohazards" will be. During the first term of current A.Y. 2020-2021, Politecnico di Milano is offering courses in mixed modality: a fraction of the total lectures is provided through remote teaching (from 40\%-60\%) and the complementary part is given "in presence." Obviously, this second section should mainly include lab, in-field activities, and technical visits. The university administration has equipped all classrooms with an integrated system able to broadcast lectures online (Cisco Webex Meetings ${ }^{\circledR}$ ). This solution also allows those students who are not able to join classes "in presence" to attend from remote.

Disregarding which modality will be possible, the experience achieved during the first edition of this course will be replicated in the future. Final assignments have been demonstrated to be a key-point for a successful PBL experience. The chance to carry them out by including data acquisition as well would make their impact even more high, as already proved in Rutzinger et al. (2018; 2020).

\section{ACKNOWLEDGEMENTS}

The authors would like to acknowledge all students from the Workshop on Monitoring Techniques for Geohazards" during A.Y. 2019-2020 who developed the assignments. Acknowledgements go to Navmatix (2020) for the free availability of GNSS mission planning tool, and to GEO4D Erasmus+ project for the supporting material on active and problem-based learning.

\section{REFERENCES}

Alvarez-Taboada, F., 2019: PBL basics: when learning begins with a problem. GEO4D Erasmus+ Project, Workshop on e-learning and PBL (Problem-Based Learning) pedagogy, Ponferrada, Spain, 1-6 April 2019, https://www.geo4d.info /results (10 October 2020).

Arosio, D., Munda, S., Tresoldi, G., Papini, M., Longoni, L., Zanzi, L., 2017: A customized resistivity system for monitoring saturation and seepage in earthen levees: installation and validation. Open Geosciences, 9, 457-467, doi:10.1515/geo2017-0035.

Arosio, D., Hojat, A., Ivanov, V.I., Loke, M.H., Longoni, L., Papini, M., Tresoldi, G., Zanzi, L., 2018: A laboratory experience to assess the 3D effects on 2D ERT monitoring of river levees. 24th Europ. Meeting of Environmental and Engineering Geophysics, Vol. 2018, No. 1, pp. 1-5, doi:10.3997/2214-4609.201802628.

Ballio, F., Brambilla, D., Giorgetti, E., Longoni, L., Papini, M., Radice, A., 2010: Evaluation of sediment yield from valley slopes: A case study. WIT Transactions on Engineering Sciences, doi:10.2495/DEB100131.
Baroni, L., Cauli, F., Donatelli, D., Farolfi, G., Maseroli, R., 2008: La Rete Dinamica Nazionale (RDN) ed il nuovo sistema di riferimento ETRF2000. Servizio Geodetico, Istituto Geografico Militare, Firenze, Italy, https:// www.igmi.org/++theme++igm/pdf/rdn_download/relazione.pdf.

Barrionuevo, L., 2019: Tools and resources of e-learning. GEO4D Erasmus+ Project, Workshop on e-learning and PBL (Problem-Based Learning) pedagogy, Ponferrada, Spain, 1-6 April 2019, https://www.geo4d.info/results (10 October 2020).

Cefalo, R., Zielinski, J.B., Barbarella, M., 2018: New Advanced GNSS and 3D Spatial Techniques. Lectures Notes in Geoinformation and Carthography, Springer, Cham, Switzerland.

Duò, L., 2019: The Teaching and Learning Innovation Program of Politecnico di Milano. GEO4D Erasmus+ Project, Seminar on Innovative Teaching at Politecnico di Milano, Milano, 11 Sept 2019, https://www.geo4d.info /results (10 October 2020).

Frukacz, M., Presl, R., Wieser, A., 2016: Pushing the sensitivity limits of TPS-based continuous deformation monitoring of an Alpine Valley. Joint Int. Symp. on Deformation Monitoring (JISDM), Vienna, Austria 30 March-1 April 2016, https:// www.fig.net/resources/proceedings/2016/2016_03_jisdm_pdf/n onreviewed/JISDM_2016_submission_81.pdf, 11 pages.

Hofmann-Wellenhof, B., Lichtenegger, H., Wasle, E., 2008: GNSS - GPS, GLONASS, Galileo \& more. Springer, Cham, Switzerland.

Hungr, O., Leroueil, S., Picarelli, L., 2014: The Varnes classification of landslide types, an update. Landslides 2014, 11, 167-194.

Ivanov, V., Arosio, D., Tresoldi, G., Hojat, A., Zanzi, L., Papini, M., Longoni, L., 2020: Investigation on the Role of Water for the Stability of Shallow Landslides - Insights from Experimental Tests. Water, 12, paper No. 1203.

Leica Geosystems, 2020a: Leica Viva TS16 - World's First Self-Learning Total Station https://leica-geosystems.com/ products/total-stations/robotic-total-stations/leica-viva-ts16 (11 October 2020).

Leica Geosystems, 2020b: Leica NA2 \& NAK2 Automatic, Optical Levels https://leica-geosystems.com/it-it/products/ levels/automatic-levels/leica-na2-nak2 (11 October 2020).

Leica Geosystems, 2020c: GNSS Systems https://leicageosystems.com/en-us/products/gnss-systems (11 October 2020).

Lienhart, W., 2017: Geotechnical monitoring using total stations and laser scanners: critical aspects and solutions. $J$. Civil Struct. Health. Monit. 7, 315-324, doi.org/10.1007/s13349-017-0228-5.

Limpach, P., Geiger, A., Raetzo, H., 2016: GNSS for Deformation and Geohazard Monitoring in the Swiss Alps. Joint Int. Symp. on Deformation Monitoring, 30 March-1 April 2016, Vienna, https://www.fig.net/resources/proceedings/2016/ 2016_03_jisdm_pdf/nonreviewed/JISDM_2016_submission_68 .pdf, 4 pages.

Longoni, L., Papini, M., Brambilla, D., Barazzetti, L., 
Roncoroni, F., Scaioni, M. Ivanov, V.I., 2016. Monitoring riverbank erosion in mountain catchments using terrestrial laser scanning. Remote Sens., 8, paper No. 241, doi: 10.3390/ rs8030241.

Hojat, A., Arosio, D., Longoni, L., Papini, M., Tresoldi, G., Zanzi, L., 2019: Installation and validation of a customized resistivity system for permanent monitoring of a river embankment. EAGE-GSM $2^{\text {nd }}$ Asia Pacific Meeting on Near Surface Geoscience \& Engineering, 22-26 April, Kuala Lumpur, 1601-177, doi:10.3997/2214-4609.201900421.

Navmatix 2020: GNSS Mission Planning http://gnssmissionplanning.com/ (10 October 2020).

Politecnico di Milano, 2020a: Civil Engineering for Risk Mitigation https://www.polimi.it/?id=6502\&anno=2020\& campus $=\&$ scuola $=\&$ corso $=437$ (9 October 2020).

Politecnico di Milano, 2020b: Ingegneria Civile per la Mitigazione del Rischio https://www.polimi.it/?id=6500\&anno= 2020\&campus $=\&$ scuola $=\&$ corso $=306$ (13 October 2020).

QGIS Development Team, 2020: QGIS - A free and opensource Geographic Information System (Software Ver. 3.10) https://www.qgis.org/en/site/ (11 October 2020).

Regione Lombardia, 2020: Geoportal of Lombardia Region Download Geographic Data http://www.geoportale.regione. lombardia.it/en/download-dati (10 October 2020).

Rutzinger, M., Höfle, B., Lindenbergh, R., Oude Elberink, S., Pirotti, F., Sailer, R., Scaioni, M., Stötter, J., Wujanz, D., 2016: Close-Range Sensing Techniques in Alpine Terrain. ISPRS Ann. Photogramm. Remote Sens. Spat. Inf. Sci., Vol. III, Part 6, 1522, doi:10.5194/isprs-annals-III-6-15-2016.

Rutzinger, M., Bremer, M., Höfle, B., Hämmerle, M., Lindenbergh, R., Oude Elberink, S., Pirotti, F., Scaioni, M., Wujanz, D., Zieher, T., 2018: Training in Innovative Technologies for Close-Range Sensing in Alpine Terrain. ISPRS Ann. Photogramm. Remote Sens. Spatial Inf. Sci., Vol. IV, Part 2, 239-246, doi:10.5194/isprs-annals-IV-2-239-2018.

Rutzinger, M., Anders, K., Bremer, M., Höfle, B., Lindenbergh, R., Oude Elberink, S., Pirotti, F., Scaioni, M., Zieher, T., 2020: Training in Innovative Technologies for Close-Range Sensing in Alpine Terrain - 3rd Edition. Int. Arch. Photogramm. Remote Sens. Spatial Inf. Sci., Vol. XLIII, Part B5-2020, 243-250, doi:10.5194/isprs-archives-XLIII-B5-2020-243-2020.

Scaioni, M., Crippa, J., Longoni, L., Papini, M., and Zanzi, L., 2017: Image-Based Reconstruction and Analysis of Dynamic Scenes in a Landslide Simulation Facility. ISPRS Ann. Photogramm. Remote Sens. Spatial Inf. Sci., Vol. IV, Part 5/W1, 63-70, doi:10.5194/isprs-annals-IV-5-W1-63-2017.

Scaioni, M., Crippa, J., Yordanov, V., Longoni, L., Ivanov, V.I., Papini, M., 2018: Some Tools to Support Teaching Photogrammetry for Slope Stability Assessment and Monitoring. Int. Arch. Photogramm. Remote Sens. Spatial Inf. Sci., Vol. XLII, Part 3/W4, 453-460, doi:10.5194/isprsarchives-XLII-3-W4-453-2018.

Schofield, W., Breach, M., 2007: Engineering Surveying - $6^{\text {th }}$ Edition. Butterworth-Heinemann (Elsevier), Oxford, 622 pages.
SPIN3 GNSS, 2020: Servizio di Posizionamento Interregionale GNSS di Regione Piemonte, Regione Lombardia e Regione Autonoma Valle d'Aosta https://www.spingnss.it/spiderweb/ frmindex.aspx (11/10/2020).

Wolf, P.R., Ghilani, C.D., 1997: Adjustment Computations: Statistics and Least Squares in Surveying and GIS. WileyInterscience.

Yordanov, V., Mostafavi, A., Scaioni, M., 2019: DistanceTraining for Image-Based 3D Modelling of Archeological Sites in Remote Regions. Int. Arch. Photogramm. Remote Sens. Spatial Inf. Sci., Vol. XLII, Part 2/W11, 1165-1172, doi:10.5194/isprs-archives-XLII-2-W11-1165-2019.

Yordanov, V., Brovelli, M.A., 2020a: Comparing Model Performance Metrics for Landslide Susceptibility Mapping. Int. Arch. Photogramm. Remote Sens. Spatial Inf. Sci., Vol. XLIII, Part B3-2020, 1277-1284, doi:10.5194/isprs-archives-XLIIIB3-2020-1277-2020.

Yordanov, V., Brovelli, M.A. 2020b: Application of Various Strategies and Methodologies for Landslide Susceptibility Maps on a Basin-Scale: The Case Study of Val Tartano, Italy. Appl. Geomat., doi:10.1007/s12518-020-00344-1.

Zhang, Z., Arosio, D., Hojat, A., Taruselli, M., Zanzi, L., 2019: Construction of a 3D velocity model for microseismic event location on a monitored rock slope. EAGE-GSM 2nd Asia Pacific Meeting on Near Surface Geoscience \& Engineering, 22-26 April, Kuala Lumpur, 304-102, doi:10.3997/22144609.201900382. 